\title{
Spectral damage model for lighted museum paintings: Oil, acrylic and gouache
}

Santiago Mayorga Pinilla a, smayorga@ucm.es

Daniel Vázquez a, dvazquez@ucm.es

Antonio Álvarez Fernández-Balbuena a, antonioa@ucm.es

Carmen Muro b, carmen.muro@museoreinasofia.es

Javier Muñoz a, jmunozlu@opt.ucm.es

a Facultad de Óptica y Optometría de la Universidad Complutense de Madrid,

C / Arcos de Jalón 118, 28037 Madrid, España.

b Departamento de Restauración, Museo Nacional Centro de Arte Reina Sofía, 28012 Madrid, España.

\footnotetext{
Abstract

A spectral aging test was developed to estimate the photochemical damage of oil, acrylic and gouache paints exposed to permanent lighting. The paints were irradiated at seven different wavelengths in the optical range to control and evaluate their spectral behaviour. To reach this objective, boxes with isolated aging cells were made. In each of box, one LED of a different wavelength and one photodiode were installed. Inside the boxes, the temperature of an exhibit area was recreated through a thermocouple sensor that controlled the temperature using a fan. The heat produced by the LED was dissipated by a thermal radiator. Moreover, to evaluate the exposure time dependence of the irradiation level, the test was performed using two different irradiation levels in ten exposure series. After each series, the spectral reflectance was measured, and the data collected for each paint and wavelength were used to develop a model of damage produced by the interaction between the spectral radiant exposure and the paint.
} 
Keywords: aging, photochemical effect, paint samples, relative damage, spectral radiant

\section{Research aims}

A spectral aging test for visible radiation was developed for oil, acrylic and gouache paints. The study was conducted at high and low levels of radiation, and the results were consistent at both levels. To conduct the test, boxes of accelerated aging using LEDs as a light source were manufactured and characterized. Considering the absorbed radiation for each sample, a theoretical spectral aging model for each type of paint was developed, showing that the damage relation produced at different wavelengths varies with different aging conditions. A theoretical model was developed for each type of paint. A further model integrating the spectral component with the temporal component was also created.

The temporal component has a significant influence in the process. If only certain some areas of a painting were restored, their aging time is different than that of the areas that were not restored. The colour shifts are higher when the paint is new. As a consequence, after some time, the colour of the restored areas will be different than the original colour. The proposed model could be applied to the development of optimized illuminant used in artworks painted with materials similar to those analysed in the present study.

\section{Introduction}

Care, preservation and exhibition of cultural heritage strongly depend on the museum environmental conditions [1, 2]. Lighting, one of the most important parameters, can also cause photochemical degradation $[3,4]$ if not properly monitored and controlled. Indeed, most organic and many inorganic substances 
change with time and with light action, as can be appreciated in processes in nature. Both artificial and natural light can produce undesirable effects in exposed materials in museums $[5,6]$. Colour change is usually the most obvious indication of lightinduced damage to cultural heritage.

Cultural heritage can be affected and damaged through photochemical effects due to at least four main factors [4]: the irradiance, the exposure time, the spectral distribution of the light and the spectral response of the exposed material.

The latter factor is difficult to determine due to the complex nature of the cultural heritage goods. Because museums have to address many different materials in different conservation statuses, the current research proposes several strategies to address this situation $[4,7,8,9$ and 10$]$.

For instance, Cuttle developed a model applied to the damage produced by light in several materials [7] and the CIE 157 defined a model to evaluate damage due to optical radiation [3, 4]. CIE 157 (model of Berlin) defines the damage suffered by an object exposed to light $D M$ as a function of the spectral irradiance of the light source $E_{d m}$, the relative spectral responsivity of each exposed material $s(\lambda)$ and the exposure time $t$,

$D M=f\left(E_{d m}, s(\lambda), t\right)$.

According to this model, $s(\lambda)$ can be expressed as,

$s(\lambda)=\exp [-b(\lambda-300)]$

where $\lambda$ is the wavelength in $\mathrm{nm}$, and the parameter $b$ is specific for each material expressed in standard CIE 157-2004. This function is normalized at a wavelength of $300 \mathrm{~nm}$.

Most of the time, the spectral responsivity of the materials does not give much practical information to optimize the light spectrum in museums because cultural 
goods are analysed as a whole. Currently, multispectral analysis of each specimen is becoming a common technique. These measurements are also more accurate and require less time [11, 12 and 13$]$.

Spectral reflectance is an important parameter to evaluate the conservation status in cultural heritage, especially in the case of paintings. Indeed, the spectral data can provide relevant information to curators about the artwork they have to restore. For example, spectral data are useful for pigment identification [14], especially when a database of frequently used pigments is available [15]. These data are then used for physical characterization, forensic work, lighting purposes [16] and others $[17,18]$. The spectral reflectance associated with other techniques can also provide information about subsurface microstructures [19]. Even in areas where colours appear similar to the naked eye, the spectral curves can show differences because metameric effects can occur [20].

Spectral reflectance is also a very important tool to evaluate the results of a retouching restoration process [21], where the only way to evaluate is the metamerismo with changes of illumination [22].

Furthermore, the painting damage can be calculated by measuring different physical and chemical parameters. One of the most useful parameters is the colour shift, which is symptomatic of chemical changes inside the material. When radiation falls onto the painted surface, only the absorbed radiation can produce a change in the material; therefore, the damage evaluation in this work was performed using this absorbed radiation.

In principle, the absorbed energy is a function of the reflected energy. Given a light source with a spectral irradiance distribution $E_{\lambda}$, falling onto a material with a 
spectral reflectance $\rho_{\lambda}$, the effective radiant exposure $H_{d m}$ can be expressed as follows:

$H_{d m}=\iint_{t, \lambda} E_{\lambda} s(\lambda) \alpha(\lambda) d t d \lambda$

where $\alpha(\lambda)=(1-[\rho(\lambda)+\tau(\lambda)])$ is the spectral absorbance, i.e., the energy absorbed by the paints. In the case of this study, the transmittance $\tau(\lambda)$ is assumed equal to zero.

An evaluation of the photochemical effect that takes into account absorbed energy implies a more sophisticated and time consuming analysis because it requires knowing the spectral reflectance factor of each cultural good, but the process would be more accurate and the results will be much better than when only irradiance of the surface is used.

The purpose of this work is to develop a model for the spectral photochemical damage produced in three common materials found in museum objects, namely, oil, acrylic and gouache. These materials are often used to retouch old paintings; therefore, the exhibition curators should be able to compare future changes in restored areas with areas where the aging is due to natural effects.

\section{Methodology and experimental setup}

Thirty-nine paints were exposed to light to test the photochemical degradation process. The paints were selected by the curators of the Reina Sofía and Thyssen Museums of Madrid according to practical criteria, based on their experience. The paint samples comprised twenty-three oil, nine acrylic and seven gouache paints. The characteristics of the paints used in this work are presented in appendix Table A.1.

Paint samples were prepared by application of a thin layer of paint onto glass plates of $250 \times 4 \times 2 \mathrm{~mm}(L, W, T)$ through a standard paint extender with constant 
thickness $120 \mu \mathrm{m}$ [23]. Paint samples were then placed in a dark room in the laboratory at an average temperature of $25^{\circ} \mathrm{C}$ for a drying process of 9 months before starting the aging test. Paint samples were put inside eleven aging boxes, each box containing 4 samples and 8 isolated areas (individual cells). Seven of these areas were irradiated and the last area was not irradiated but was used as a control zone. To increase the luminous uniformity, these cells had diffused white walls. As a radiation source for the aging process, seven LEDs with central wavelengths of 447, 470, 505, 530, 590, 617 and $627 \mathrm{~nm}$ were used in the different isolated cells (Fig. 1). Current new lighting systems based on $L E D$ sources permit spectral distributions optimized to the requirements of museum exhibition and conservation and also offer other important advantages, such as low energy consumption and longer life times. [24]

This configuration assured a specific irradiation level for each cell according to the $L E D$ characteristics, and the variation was taken into account by measuring the spectral power distribution of 77 LEDs (eleven aging boxes, seven LEDs in each aging boxes) using a Stellarnet EPP2000 spectrophotometer.

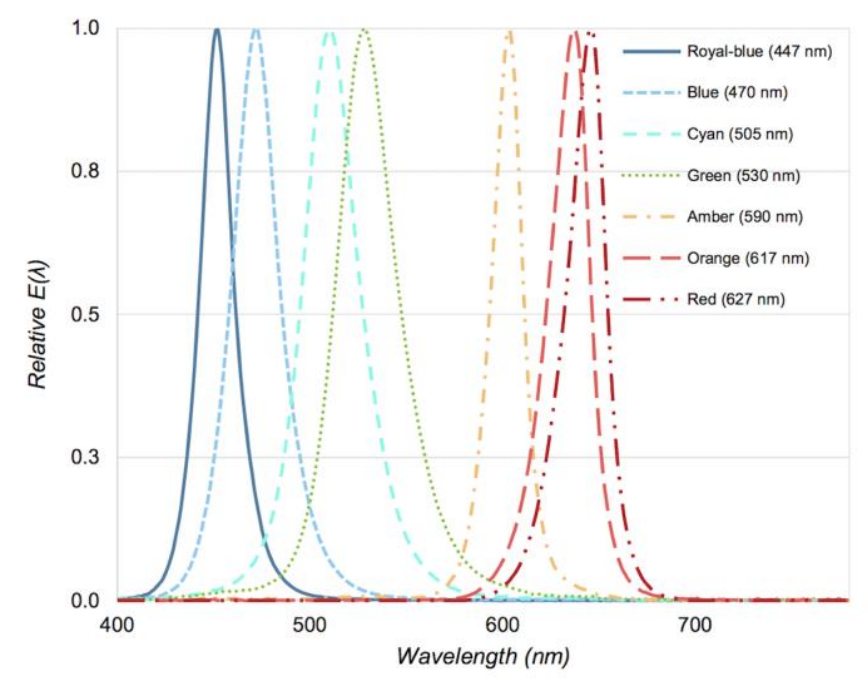

Fig. 1. Normalized spectral distribution of the 7 LED sources installed inside the aging boxes. 
The aging process was tested at two different irradiation levels over the paint samples, in 10 sessions: 6 sessions at low irradiation level $(L I L)$ and 4 sessions at high irradiation level $(H I L)$. During the aging process, the spectral reflectance of each area was measured.

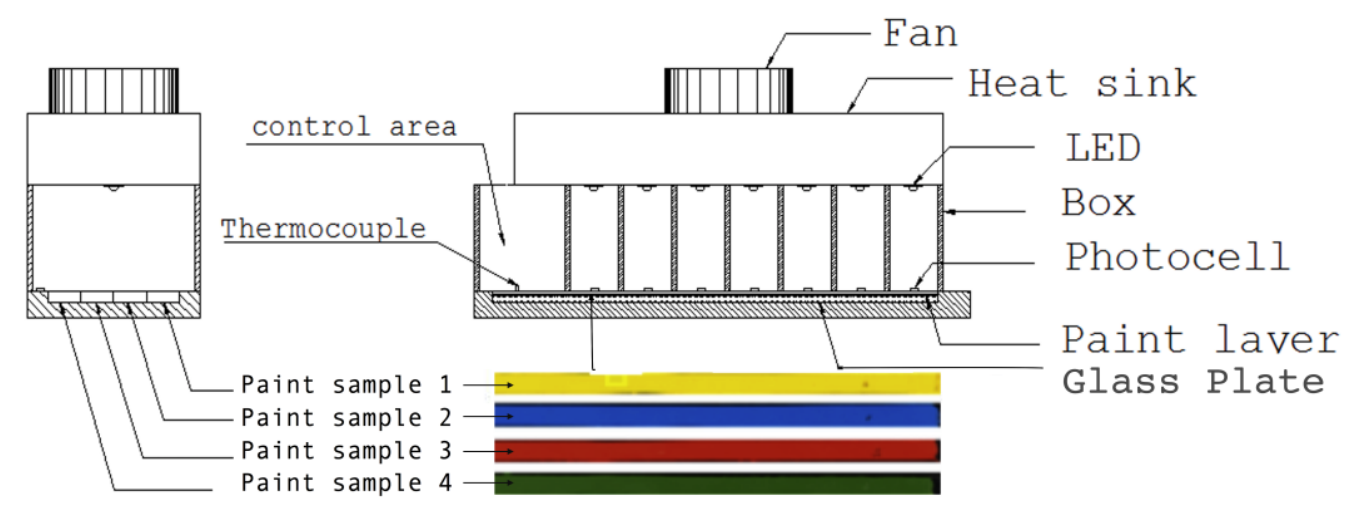

Fig. 2. Experimental setup schematic and fragments of paint samples used in the research.

To detect and to monitor possible breakdowns or an output radiation flux decrease from the $L E D s$, a photodiode was installed in each isolated cell of each box. Because it was not possible to assure an identical output flux for all $L E D s$ at the same wavelength, the output flux of each $L E D$ in each cell was measured during the whole aging test over the paint samples plane and inside each cell using a Thorlabs PM100 USB power meter. Measurements were made at the paint samples centres of each cell (area of $0.5 \mathrm{~mm}$ radii). Table 1 shows an average irradiation level within the spectral range of $60.87 \mathrm{Wm}^{-2}$ for $L I L$ and $158 \mathrm{Wm}^{-2}$ for $H I L$, with both values lower than $500 \mathrm{Wm}^{-2}$, the value proposed by ASTM D 4303-10 norm [25], and lower than $1440 \mathrm{Wm}^{-2}$, proposed by ISO 11341: 2004 norm [26].

Furthermore, the irradiance uniformity of each cell was measured experimentally for each wavelength, finding the highest standard deviation at the radiation level at $447 \mathrm{~nm}$ and the lowest at $590 \mathrm{~nm}(\sigma=1.164)$. 
Although the irradiance value at a certain wavelength varied with time on the exposed paint samples, the value used for the calculation of the total radiation was that measured experimentally for each position inside the cell and for each wavelength.

To avoid heating of the paint surface, each box was provided with an aluminium heat sink with a fan. The temperature was measured in each aging box by means of a thermocouple installed inside the control area.

Fig. 2 shows a schematic of the aging boxes.

\begin{tabular}{c|c|c|}
$\lambda(\mathbf{n m})$ & Low $\left(\mathbf{W m}^{-2}\right)$ & $\operatorname{High}\left(\mathbf{W m}^{-2}\right)$ \\
\hline 447 & 139.5 & 344.5 \\
470 & 106.8 & 240.2 \\
505 & 61.8 & 131.2 \\
\hline 530 & 36.8 & 76.7 \\
590 & 17.2 & 22.9 \\
\hline 617 & 66.2 & 153.0 \\
\hline 627 & 58.7 & 139.4 \\
\hline
\end{tabular}

Table 1: Average irradiance values in each cell for LIL and HIL.

\subsection{Characterization of the paint spectral reflectance}

Spectral reflectance was measured using a $P R-655$ spectrophotometer equipped with an $m s 2.5 x$ objective. The measurement area was a circle with a radius of $0.5 \mathrm{~mm}$ over the paint samples. Before measuring the spectral reflectance for each box, a calibrated reflectance standard of $99.8 \%$ (Labsphere) was measured and used as a spectral reference. It is assumed that in every paint sample, the reference zone changes its spectral reflectance during the whole process. The paint samples were always measured at the same point using a micrometric displacement system, and the measured spectral reflectance was an average of three different measurements. As will be shown, even the zone not exposed to the visible radiation suffered some changes along the drying period due 
to the ambient temperature and to the situations described later, in which light is not involved.

Taking a specific area of the paint samples, the spectral reflectance in the control area (named as the zero area) at the beginning, i.e., without damage, is named as $\rho_{\lambda}^{0,0}$. A second measurement was taken in a non-radiated area (zero area) $\rho_{\lambda}^{0, \mathrm{i}}$ to verify whether the reflectance was modified (Fig. 3) and to apply these variations to the rest of the zones. The spectral change without light exposure due to non-photochemical action was evaluated as

$\Delta \rho_{\lambda}^{0, \mathrm{i}}=\rho_{\lambda}^{0,0}-\rho_{\lambda}^{0, \mathrm{i}}$

If the spectral reflectance measured for a paint sample in a cell $c$ at time $i$ was $\rho_{\lambda}^{\mathrm{c}, \mathrm{i}}$, then the reflectance change is

$\Delta \rho_{\lambda}^{\mathrm{c}, \mathrm{i}}=\rho_{\lambda}^{\mathrm{c}, 0}-\rho_{\lambda}^{\mathrm{c}, \mathrm{i}}$

Because these spectral changes are due to photochemical and nonphotochemical effects, the photochemical spectral changes can be determined by subtracting the previously deduced non-photochemical changes. Therefore,

$\Delta \rho_{\lambda}^{\mathrm{pc,i}}=\Delta \rho_{\lambda}^{\mathrm{c}, \mathrm{i}}-\Delta \rho_{\lambda}^{0, \mathrm{i}}$

where the upper index $c$ means the number of the cell (wavelength-dependent), $i$ indicates the number of the aging cycle and $p$ makes reference to the photochemical effect. 


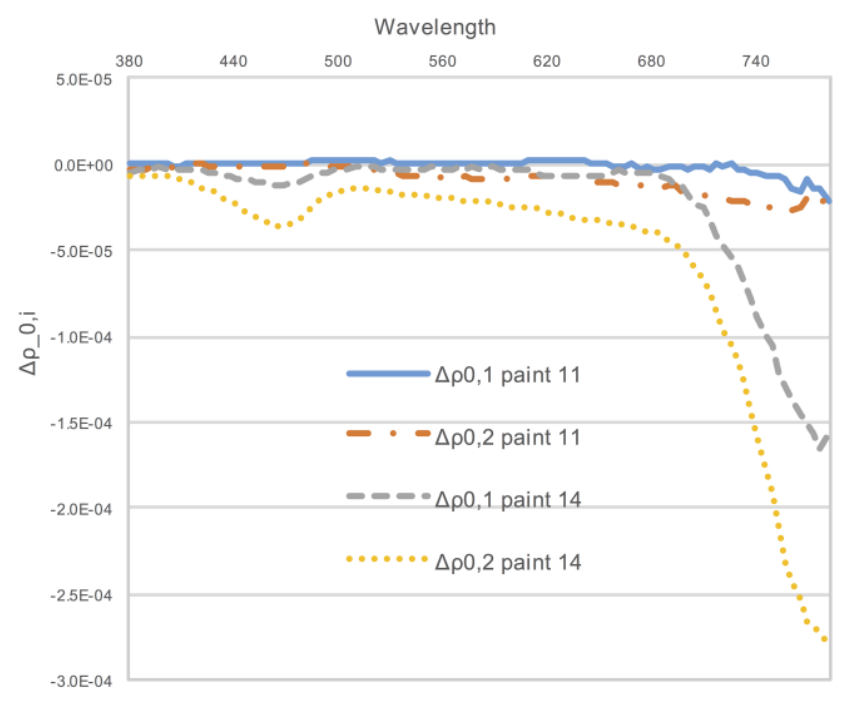

Fig. 3. Diagram showing the reflectance differences between samples 11 and 14 . The reflectance measurements performed in the non-illuminated zone (i.e., with no influence from the photochemical effect) are represented, from the beginning of the session with respect to the first measurement $\left(\Delta \rho^{0,1}\right)$ and from the beginning of the session with respect to the second measurement $\left(\Delta \rho^{0,2}\right) . \Delta \rho^{0,1}$ sample 11 and $\Delta \rho^{0,1}$ sample 14 refer to the continuous line and dashed line, respectively. $\Delta \rho^{0,2}$ sample 11 and $\Delta \rho^{0,2}$ sample 14 refer to the dashed-dotted line and dotted line, respectively.

From the obtained reflectance values, chromatic coordinates $L^{*} a^{*} b^{*}$ were calculated because it is the most frequent space colour applied in cultural heritage, according to CIE 15:2004, and the colour space CIELAB [4] at two different times (initial and $i$ ) and $\Delta \mathrm{E}_{\mathrm{ab}}^{*}$ (colour difference) was calculated, according to the formula:

$\Delta \mathrm{E}_{\mathrm{ab}}^{*}=\sqrt{\left(\Delta \mathrm{L}^{*}\right)^{2}+\left(\Delta \mathrm{a}^{*}\right)^{2}+\left(\Delta \mathrm{b}^{*}\right)^{2}}$

\subsection{Relative damage $(R d)$}

A relative damage factor $R d$ was introduced to give a value of the damage on the paints produced by the aging process related to the colour shift. $R d$ is defined as $\mathrm{Rd}=\frac{\Delta \mathrm{E}_{\mathrm{ab}}^{*}}{\mathrm{H}_{\mathrm{dm}}}$

where $\Delta \mathrm{E}_{\mathrm{ab}}^{*}$ is the colour difference (dimensionless), and $H_{d m}$ is the effective radiant exposure in $\mathrm{Whm}^{-2}$. The parameter $R d$, expressed in $\mathrm{m}^{2} \mathrm{~W}^{-1} \mathrm{~h}^{-1}$, 
provides the relation of the colour shift of the paint as a function of the total absorbed light radiation. A low value of this parameter signifies that the colour of the paint is very stable at that moment.

Because the painting damage behaviour is different based on the material (oil, acrylic and gouache), the materials were studied separately to obtain models for each material.

As a reference, if a painting is exhibited in a museum for 3500 hours per year and is illuminated with an illuminant $A^{1}$ with an average illuminance of $100 \mathrm{~lx}$ and a calculated equivalent irradiance of $0.6408 \mathrm{Wm}^{-2}$, in 10 years of exposure, it will accumulate $3.5 \times 10^{6} \mathrm{lxh}$, with an effective radiant exposure $H_{d m}=$ $22026 \mathrm{Whm}^{-2}$.

In the ten measurement sessions for all paint samples, the irradiance values for the same wavelength (number of cell $i$ ) were similar. Although the values obtained have tolerances within the norm ISO 11341:2004 [26], the $H_{d m}$ values, which take into account the absorbed energy, are different, even for the same wavelength in different paint samples. This difference is because spectral absorbance depends on the type of paint (oil, acrylic and gouache) because they do not behave in a homogeneous way.

In the first measurement of each paint sample, the $H_{d m}$ level was different because each paint sample absorbs a certain amount of energy and has different aging and $R d$ factors as a function of the source wavelength and the photochemical characteristics of the paint.

1 Illuminant $A$ was chosen as an example because it is the most commonly used in museum illumination due to its high chromatic reproduction index (CRI). Any other illuminants in the CIE can be used for the calculations. 
In the initial phase of the aging samples, the changes in $R d$ are accelerated compared to the following stages, in which samples remain more stable. This result is consistent with the reciprocity law deduced by Hoyo and Mecklenburg, 2011 (27), even though in our case this law has to be assumed dynamic.

\section{Results}

The results are the weighted average of the irradiance and colour shift of all paint samples, taking into account only the absorbed radiation as a whole in the complete wavelength range of the study $(400-780 \mathrm{~nm})$.

\subsection{Relative damage measured for oil, acrylic and gouache paint samples}

In this research, calculations of the percentiles $5 \%(R d=5 \%), 95 \%(R d=$ 95\%) and the $R d$ average value ( $R d_{-}$Mean) for all paints were performed. Figure 4 shows the results obtained for oil and gouache paints.

Because the colour shifts in the initial phase are greater than in the final phases, presenting the graphs on a natural logarithmic scale enhances the visualization and understanding of the data.

A new variable has been defined as $X=\ln \left(H_{d m}\right)$, e.g., $X=10$ if $H_{d m}=22026$. The $H_{d m}$ data used in this research go from $X=4$ to $X=11$, values derived from the amount of energy $E$ irradiated onto the paint samples. 

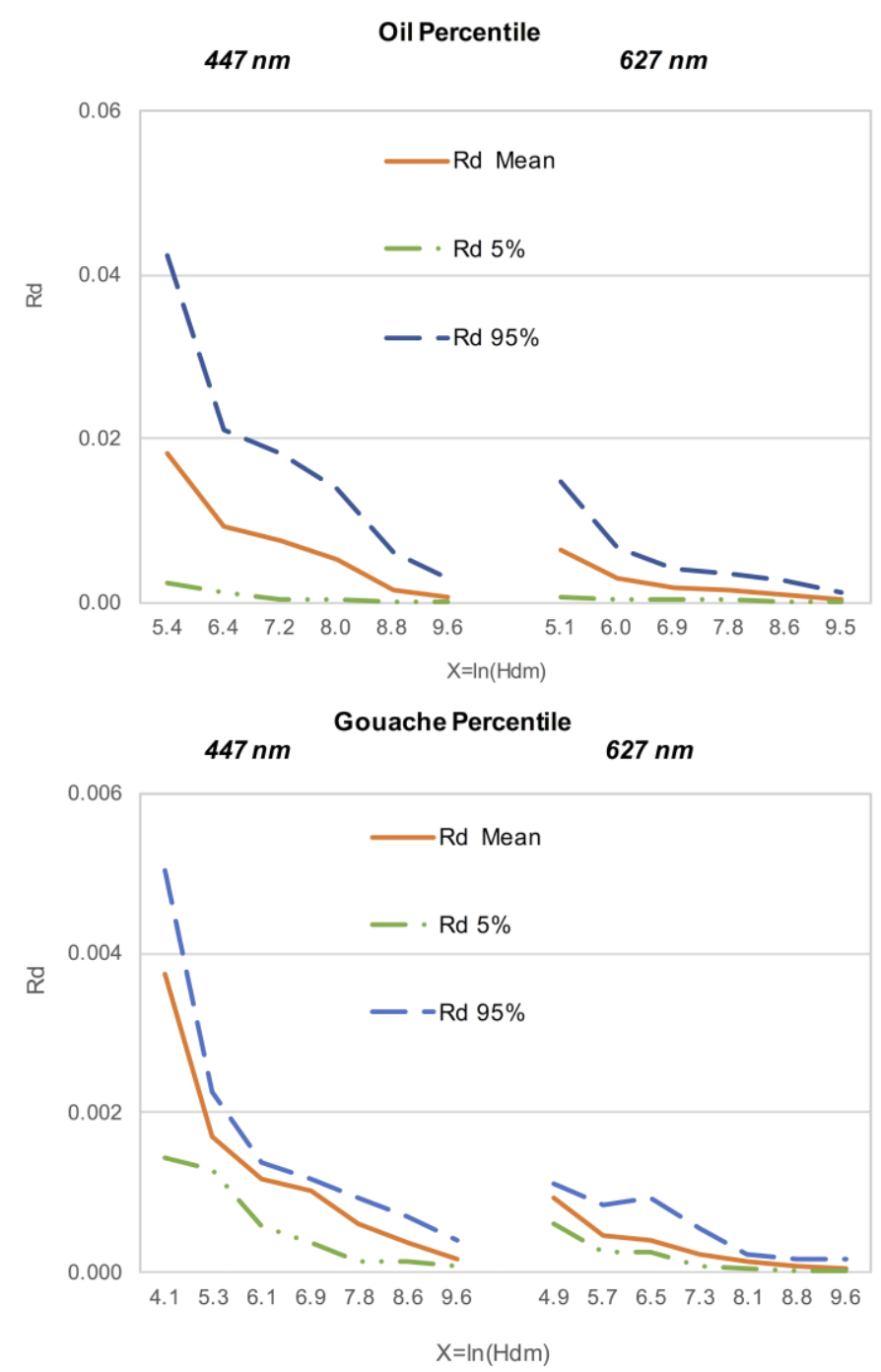

Fig. 4. Percentiles. Oil, LED $447 \mathrm{~nm}$ and LED $627 \mathrm{~nm}$ and gouache, LED $447 \mathrm{~nm}$ and LED $627 \mathrm{~nm}$. Rd in $m^{2} W^{-1} h^{-1}$.

Fig. 5 shows the calculated values of $R d$ with respect to $\ln \left(H_{d m}\right)$ for oil paint samples. These values have been derived from the irradiance measurements from equations (3) and (8). 


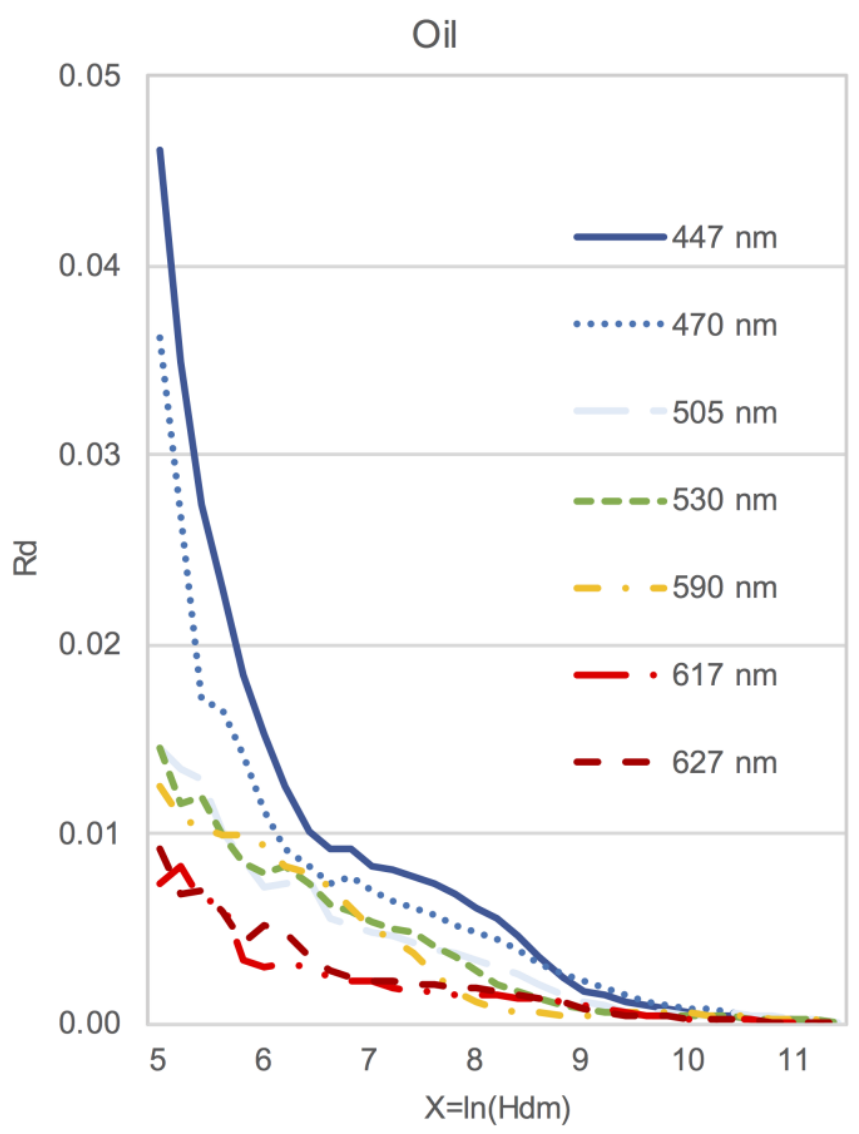

Fig. 5. Average value of the Rd value calculated from the obtained measurements for oil paintings. Rd in $m^{2} W^{-1} h^{-1}$.

Fig. 6 shows the $R d$ values after a linear regression according to the model proposed in equation (11) for oil and gouache.

\subsection{Proposed model}

\subsubsection{Proposed model for $R d$}

In this research, and with the obtained values $R d$ and $H_{d m}$, a general model for $R d$ is proposed for each type of paint, which is the result of a mathematical fitting between the relative damage $R d$ and $X=\ln \left(H_{d m}\right)$, such that $R d=\mathrm{e}^{\left[k_{1} X+k_{2}\right]}$

where $k_{1}$ and $k_{2}$ are obtained from the linear fitting between $R d$ and $H_{d m}$ with both parameters derived from equations (3) and (8). 
(The characteristics of $k_{1}$ and $k_{2}$ parameters used in this work are presented in appendix Table A.2.)

\subsubsection{Damage spectral model}

The model proposed by CIE 157 [4] shows a spectral relationship between damage and wavelength [equation(2)]. In this CIE model, the material responsivity is given by a scale factor (parameter $b$ ). Because the minimum wavelength used in this aging test was $447 \mathrm{~nm}$, the relative damage factor at a certain wavelength $\lambda_{i}\left(\operatorname{Rd}\left(\lambda_{\mathrm{i}}\right)\right)$ has been defined in this work as a function of the relative damage at the initial wavelength $\left(R d\left(\lambda_{1}\right)\right)$, where $\lambda_{1}=447 \mathrm{~nm}$.

$\operatorname{Rd}\left(\lambda_{\mathrm{i}}\right)=\operatorname{Rd}\left(\lambda_{1}\right) \mathrm{f}(\lambda)$

and $f(\lambda)$ is the relative spectral responsivity [equation (2)]. Therefore,

$\operatorname{Rd}\left(\lambda_{\mathrm{i}}\right)=\operatorname{Rd}\left(\lambda_{1}\right) \mathrm{e}^{\left[-\mathrm{b}_{\lambda}\left(\lambda_{\mathrm{i}}-447\right)\right]}$

The scale factor $b$ of the previous equation [equation (11)] can be calculated as follows:

$b(\lambda)=\frac{-\ln \frac{\operatorname{Rd}\left(\lambda_{\mathrm{i}}\right)}{\operatorname{Rd}\left(\lambda_{1}\right)}}{\left(\lambda_{\mathrm{i}}-\lambda_{1}\right)}$

From the data obtained in this research, it can be deduced that the factor $b$ is not constant in time. Therefore, the ratio between the relative damage for two different wavelengths $\left(R d\left(\lambda_{1}\right) / R d\left(\lambda_{2}\right)\right)$ and two different effective radiant exposures $\left(H_{d m 1}\right.$ and $\left.H_{d m 2}\right)$ is not constant; for the same paint, the parameter $b$ varies with time. 

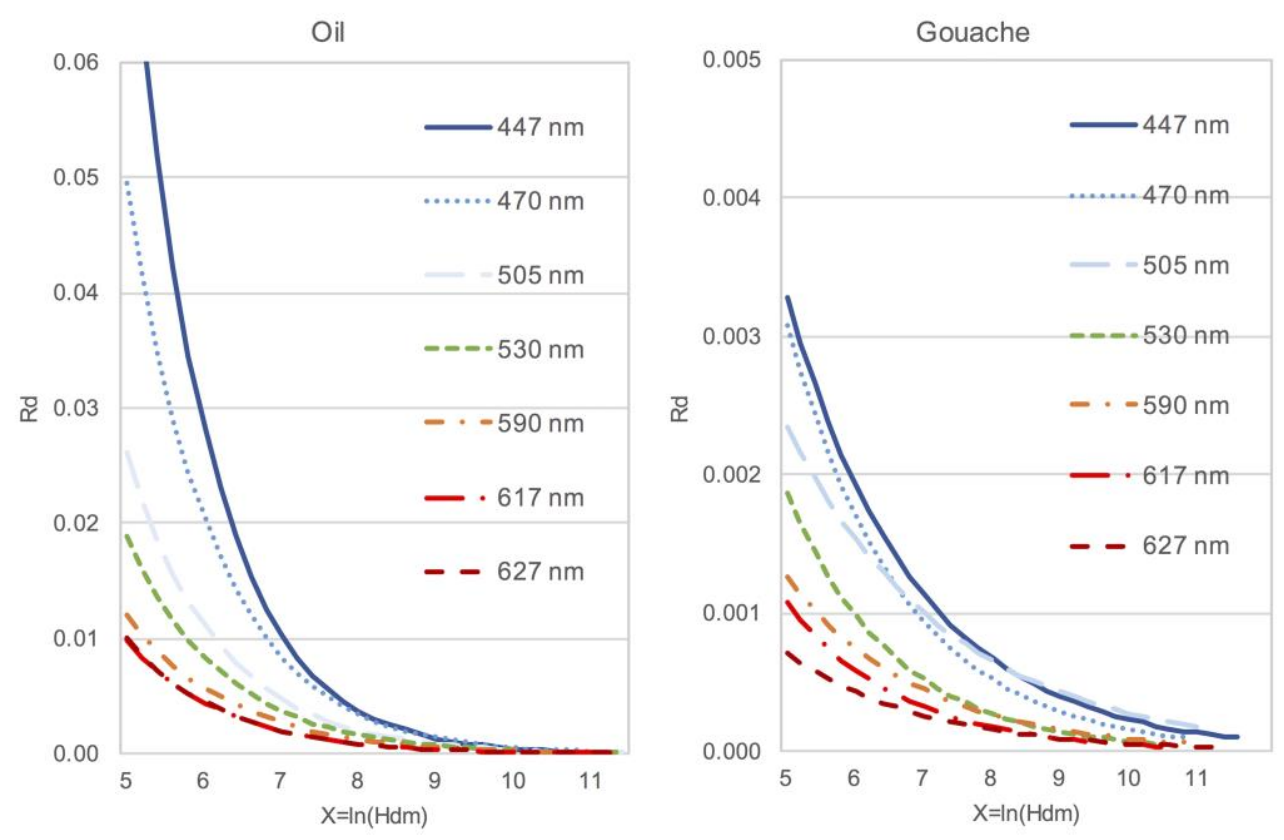

Fig. 6. Rd value from the proposed model for oil and gouache paints. In both cases, the wavelengths referred to in the research are used. Relative damage in $m^{2} W^{-1} h^{-1}$.

As seen in Fig. 6, the results indicate that for gouache paints, the colour change is lower than when oil paints are used. For instance, for $X=5$, $R d_{L E D(447 \mathrm{~nm})}=0.051$ for oil and $R d_{L E D(447 \mathrm{~nm})}=0.018$ for acrylic, whereas for gouache paint, $R d_{L E D(447 \mathrm{~nm})}=0.0023$, i.e., the relative damage is 2.83 and 22.1 times larger when using oil paints than using acrylic and gouache paint, respectively. In the case of $\Delta \mathrm{E}_{\mathrm{ab}, \mathrm{oil}(447 \mathrm{~nm})}^{*}=7.56$ for oil, the colour change is visible. According to different bibliographic references, values between 1 and 3 are in the range where the human eye is able to distinguish a colour change [4, 28-30]. However, for $\lambda=627 \mathrm{~nm}$, the $R d$ value is $R d_{L E D(627 \mathrm{~nm})}=0.0072$ for oil, $R d_{L E D(627 \mathrm{~nm})}=0.0063$ for acrylic and $R d_{L E D(627 \mathrm{~nm})}=0.0007$ for gouache, i.e., the relative damage is 1.1 times larger when using oil paints than using acrylic and 10.28 times larger than using gouache paint. $\Delta \mathrm{E}_{\mathrm{ab}, \mathrm{oil}(627 \mathrm{~nm})}^{*}=1.07$ for oil is on the threshold of being able to distinguish the colour change. For a 
more advanced aging $(X=10)$, the damage at $447 \mathrm{~nm}$ is 6.1 times greater in oil than in gouache and 5.3 times larger in acrylic than in gouache, whereas at $627 \mathrm{~nm}$, the differences are 2.36 and 3.43 times, respectively. For all cases, the units of $R d$ are given in $\mathrm{m}^{2} \mathrm{~W}^{-1} \mathrm{~h}^{-1}$.

If an oil paint is illuminated with monochromatic light of $100 \mathrm{~lx}$ as an average during ten years ( $3500 \mathrm{~h} /$ year) with a $627 \mathrm{~nm} L E D$, the irradiance will be $0.79 \mathrm{Wm}^{-2}$, whereas if the $L E D$ wavelength is $447 \mathrm{~nm}$, the irradiance will be $2.72 \mathrm{Wm}^{-2}\left(\Delta \mathrm{E}_{\mathrm{ab}}^{*}\right.$ and $R d$ after ten years are shown in Table 2). Each wavelength has a different $H_{d m}$ and therefore the aging will be different.

\begin{tabular}{|c|c|c|c|c|c|}
\hline $\begin{array}{l}\text { Wavelength } \\
\text { (nm) }\end{array}$ & $\begin{array}{c}E \\
\left(\mathbf{W m}^{-2}\right)\end{array}$ & $\begin{array}{c}\boldsymbol{H}_{d m} \\
\left(\mathbf{W h m}^{-2}\right)\end{array}$ & $X=\ln \left(H_{d m}\right)$ & $\begin{array}{c}R d \\
\left(\mathbf{m}^{2} \mathbf{W}^{-1} \mathbf{h}^{-1}\right)\end{array}$ & $\Delta E_{a b}^{*}$ \\
\hline 447 & 2.72 & 95200 & 11.46 & $9.1077 e-005$ & 8.67 \\
\hline 627 & 0.79 & 27650 & 10.23 & $1.2513 \mathrm{e}-004$ & 3.46 \\
\hline
\end{tabular}

Table 2: Relative Damage value $(R d)$ and colour difference $\Delta \mathrm{E}_{\mathrm{ab}}^{*}$, for two types of illumination, an LED of $447 \mathrm{~nm}$ and LED of $627 \mathrm{~nm}$, after ten years of aging for oil paintings.

\subsection{Application of $\boldsymbol{R d}$ for illumination}

This study was conducted using seven monochromatic sources, but when the incident light is not monochromatic, to calculate the relative damage $R d$ for certain exposure times $\left(t_{1}, t_{2}, \ldots, t_{n}\right)$ at a certain wavelength, a fitting of the data was performed to interpolate for each specific wavelength, as seen in Fig. 7. 


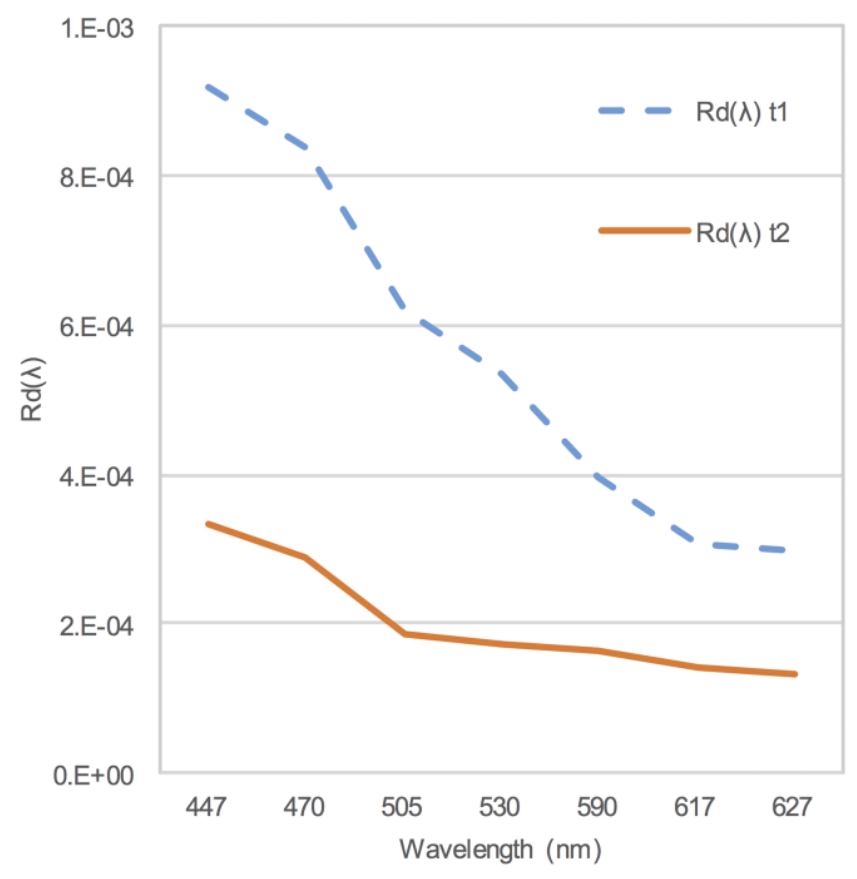

Fig. 7. $R d(\lambda)_{t 1}$ and $R d(\lambda)_{t 2}$ dependence on the wavelength for $X_{t 1}=9$ and $X_{t 2}=10$. Fitting of the data from each LED used (from $447 \mathrm{~nm}$ to $627 \mathrm{~nm}$ ). Spectral relative damage $R d(\lambda)$ in $W^{-1} h^{-1} m^{2} \mathrm{~nm}^{1}$.

When the light is not monochromatic, the most exact solution should be established by assuming the spectral energy distribution used in that case $(E(\lambda))$, and by making a weighted proportion with the values of $\operatorname{Rd}(\lambda)$. The $R d$ total $\left(R d_{\text {Tsource }}\right)$ produced by the total irradiance of the illuminant source used $\left(E_{\text {Tsource }}\right)$ can be expressed as

$\operatorname{Rd}_{\text {Tsource }}=\frac{\sum(\mathrm{E}(\lambda) \operatorname{Rd}(\lambda))}{\mathrm{E}_{\text {Tsource }}}$

with $R d_{\text {Tsource }}$ in $\mathrm{m}^{2} \mathrm{~W}^{-1} \mathrm{~h}^{-1}, E(\lambda)$ in $\mathrm{Wm}^{-2} \mathrm{~nm}^{-1}, R d(\lambda)$ in $\mathrm{W}^{-1} \mathrm{~h}^{-1} \mathrm{~m}^{2} \mathrm{~nm}$ and $E_{\text {Tsource }}$ in $\mathrm{Wm}^{-2}$. 

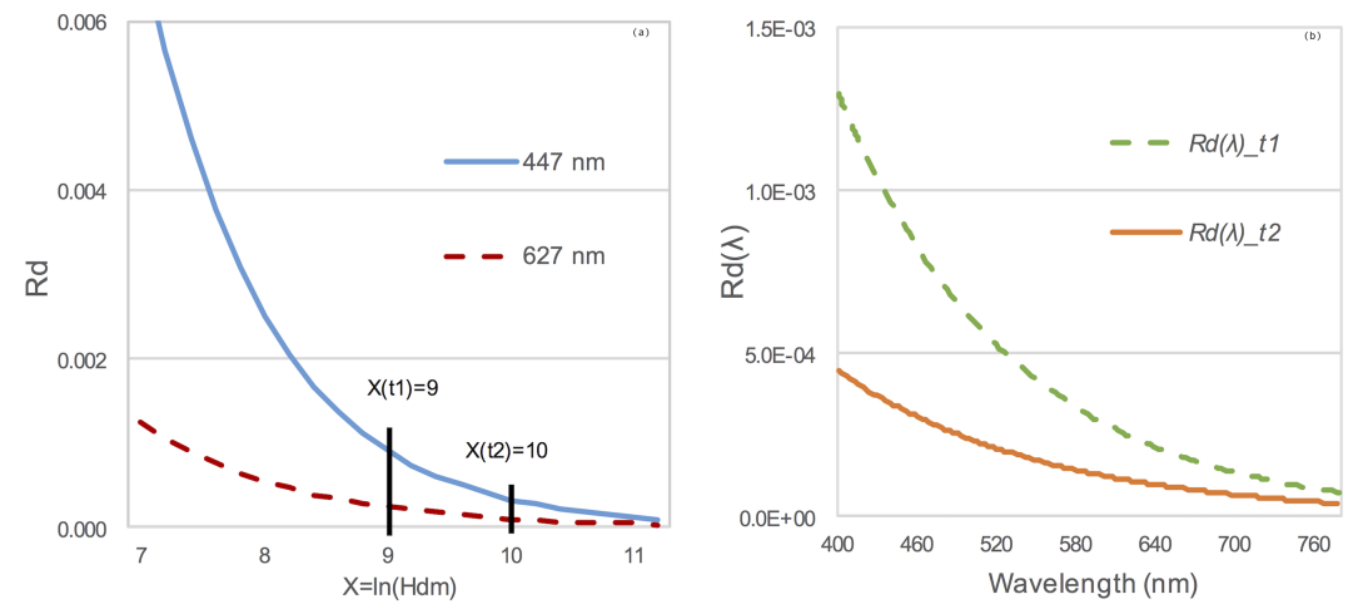

Fig. 8. (left) $R d$ values for red and blue LEDs according to the proposed model for oil. Values corresponding to $X_{t 1}=9$ and $X_{t 2}=10$ are marked. Relative damage in $m^{2} W^{-1} h^{-1}$. (right) Value of spectral Rd $\left(R d(\lambda)_{t 1}\right.$ and $\left.R d(\lambda)_{t 2}\right)$ for the moment $X_{t 1}$ (dotted line) and $X_{t 2}$ (continuous line). Spectral relative damage $(R d(\lambda))$ in $W^{-1} h^{-1} m^{2} n m$.

Applying the example in section 3.2 to a real case, if an oil paint is illuminated with illuminant $A$ (approximated to a tungsten lamp) at $100 \mathrm{~lx}$ and the value of $R d$ after certain time needs to be known, e.g., when the paint has been exposed to certain amount of radiation, with the proposed model, one can determine the $R d$ value for this illuminant. As an example, two radiation levels at different times were used, in particular, with $X_{t 1}=9$ and $X_{t 2}=10$.

Fig. 8(a) represents the model proposed with the values $X_{t 1}$ and $X_{t 2}$. The continuous and dotted lines represent the $R d$ for LEDs at 447 and $627 \mathrm{~nm}$, respectively. To use the model, the value of equation (7) $R d_{\operatorname{LED}(447 \mathrm{~nm})}=$ $\mathrm{e}^{\left(k_{1} X+k_{2}\right)}$ is applied, using the $R d$ value of the $L E D$ at $447 \mathrm{~nm}$. However, any other value can be used as a reference $R d=\mathrm{e}^{\left.\left(k_{1} X+k_{2}\right)\right)}$, with $X$ either $X_{t 1}=9$ or $X_{t 2}=$ 10, dependent on the amount of irradiance (time) to which the paint samples have been exposed.

If an $L E D$ at $447 \mathrm{~nm}$ is used, then $k_{1}=-1.0080$ and $k_{2}=2.60696$. 
The $R d$ value of an $L E D$ at $447 \mathrm{~nm}$ is $R d_{L E D(447 \mathrm{~nm})}=9.17 \mathrm{e}^{-04}$ for $X_{t 1}$ and $3.98 \mathrm{e}^{-04} \mathrm{~m}^{2} \mathrm{~W}^{-1} \mathrm{~h}^{-1}$ for $X_{t 2}$, whereas $R d_{L E D(627 \mathrm{~nm})}=2.95 \mathrm{e}^{-04}$ and $1.13 \mathrm{e}^{-04}$ $\mathrm{m}^{2} \mathrm{~W}^{-1} \mathrm{~h}^{-1}$, for $X_{t 1}$ and $X_{t 2}$, respectively.

The spectral values for $R d$ using the model can be derived from equation(11) $\operatorname{Rd}\left(\lambda_{\mathrm{i}}\right)=\operatorname{Rd}_{\mathrm{LED}(447 \mathrm{~nm})} \mathrm{e}^{\left[-\mathrm{b}_{\mathrm{t} 1 \text { model }}\left(\lambda_{\mathrm{i}}-\lambda_{1}\right)\right]}=9.17 \mathrm{e}^{\left[-0.0045\left(\lambda_{\mathrm{i}}-447\right)\right]}$, for $X_{t 1}=9$

where $\lambda_{\mathrm{i}}$ is a wavelength between 400 and $780 \mathrm{~nm}, \mathrm{~b}_{\mathrm{X}_{\mathrm{t} 1 \text { model }}}$ is the parameter obtained after using the model described in 3.4 and $\operatorname{Rd}\left(\lambda_{\mathrm{i}}\right)$ is the spectral relative damage. As seen in Fig. 8(b), a shorter radiation wavelength provides a larger energetic value, i.e., the paints age more rapidly than when using longer wavelength radiation. If we take into account these values and want to know how much illuminant $A$ (or any other illuminant) changes the relative damage, the following expression can be applied

$\operatorname{Rd}_{\mathrm{T}_{-} \text {illuA }}=\frac{\sum\left(\mathrm{E}\left(\lambda_{\mathrm{i}}\right) \operatorname{Rd}(\lambda)\right)}{\mathrm{E}_{\mathrm{T}_{-} \text {illuA }}}=0.00025 \mathrm{~m}^{2} \mathrm{~W}^{-1} \mathrm{~h}^{-1}$, for $X_{t 1}=9$

$R d_{T_{-} i l l u A}$ is the value of the relative damage for illuminant $A$. Table 3 shows the results for $X_{t 1}$ and $X_{t 2}$.

\begin{tabular}{|c|c|c|c|c|c|c|}
\hline Illuminant & $\begin{array}{c}\text { Paint } \\
\text { samples }\end{array}$ & $X=\ln \left(H_{d m}\right)$ & $\begin{array}{c}\boldsymbol{H}_{\boldsymbol{d m}} \\
\left(\mathrm{Whm}-{ }^{-2}\right)\end{array}$ & $\begin{array}{c}\boldsymbol{R} d_{\lambda\left(L E D \_447 n m\right)} \\
\left(\mathbf{W}^{-1} \mathbf{h}^{-1} \mathbf{m}^{2} \mathbf{n m}^{1}\right)\end{array}$ & $\begin{array}{c}\boldsymbol{b} \\
\text { (according to } \\
\text { model) }\end{array}$ & $\begin{array}{l}\boldsymbol{R} \boldsymbol{d}_{\boldsymbol{T}_{\text {illluA}} \boldsymbol{A}} \\
\left(\mathrm{m}^{2} \mathrm{~W}^{-1} \mathrm{~h}^{-1}\right)\end{array}$ \\
\hline \multirow{6}{*}{$\begin{array}{c}\text { Illuminant } \\
A \text { (LED } 447 \\
\text { nm) }\end{array}$} & \multirow{2}{*}{ Oil } & $X_{t 1}=9$ & 8103 & $9.17 e-04$ & 0.0074 & $2.51 \mathrm{E}-04$ \\
\hline & & $X_{t 2}=10$ & 22026 & $3.98 \mathrm{e}-04$ & 0.0062 & $1.08 \mathrm{E}-04$ \\
\hline & \multirow{2}{*}{ Acrylic } & $X_{t 1}=9$ & 8103 & $4.95 \mathrm{e}-04$ & 0.0055 & $1.82 \mathrm{E}-04$ \\
\hline & & $X_{t 2=10}$ & 22026 & $1.99 \mathrm{e}-04$ & 0.0050 & $7.84 \mathrm{E}-05$ \\
\hline & \multirow{2}{*}{ Gouache } & $X_{t 1}=9$ & 8103 & $2.73 \mathrm{e}-04$ & 0.0042 & $1.24 \mathrm{E}-04$ \\
\hline & & $X_{t 2}=10$ & 22026 & $1.61 \mathrm{e}-04$ & 0.0035 & $7.31 \mathrm{E}-05$ \\
\hline
\end{tabular}

Table 3: Values of Rd with the proposed model in a room illuminated with illuminant $A$ at $100 \mathrm{~lx}\left(R d_{T_{-} \text {illuA }}\right)$ and LED of $447 \mathrm{~nm} \operatorname{Rd}(\lambda)$, and values of $b$ for the proposed model, for two aging times $t_{1}=9$ and $t_{2}=10$, corresponding to $X_{t 1}=9$ and $X_{t 2}=10$, respectively, over oil, acrylic and gouache paints. 
Similar to that described for the oil application, if the acrylic paint samples are radiated with an illuminant $A$ at $100 \mathrm{~lx}$ and with an equivalent quantity at $X_{t 1}=$ 9 and $X_{t 2}=10$, the $R d$ total value calculated using the model is the same as that used for oil. The values $k_{1}=-0.9128$ and $k_{2}=0.6037$ for the $R d$ calculation are used with an $L E D$ at $447 \mathrm{~nm}$ in acrylic samples. Table 3 shows the obtained results.

Continuing with the application, if the gouache samples are radiated with illuminant $A$ at 100 lx and with an equivalent quantity at $X_{t 1}=9$ and $X_{t 2}=10$, the $R d$ total value calculated using the model is the same as that used for oil. Values of $k_{1}=-0.5294$ and $k_{2}=-3.4404$ for the $R d$ calculation are used with an $L E D$ at $447 \mathrm{~nm}$ in the gouache samples. The spectral values of $R d$ of the model for $X_{t 1}$ and $X_{t 2}$ are presented in table 3.

\subsection{Time dependence of $b$ parameter}

Fig. 9 emphasises the calculation of the modified $b(\lambda)$ parameter for each wavelength obtained with equation (12) with respect to that proposed by CIE 157. The $b(\lambda)$ value changes with $R d$ and with respect to the wavelength, showing the same trend in all cases.

When the paint is new, the difference between $R d$ at a specific wavelength $\left(\lambda_{i}\right)$ and $R d$ at the reference wavelength $\left(\lambda_{1}\right)$ is higher than when the paint is older. In the same way, the $b$ parameter has a strong time dependence and is lower when the paint is old, which means that the difference at the two wavelengths is less important. The damage spectral analysis is therefore less relevant for old paintings. 


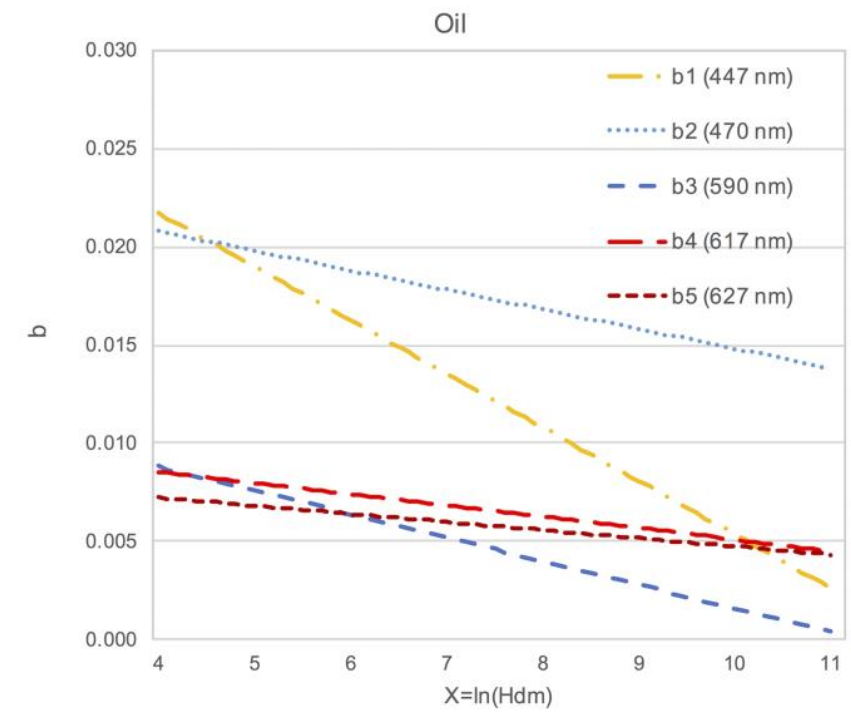

Fig. 9. Values of $b(\lambda)$ for oil for each wavelength of the source used in this study.

This difference allows the use of a linear accessory to obtain a $b$ parameter that is not wavelength dependent (dotted line in Fig. 10). The corresponding equation for oil is

$\mathrm{b}_{\mathrm{oil}}=-0.0012 \ln \left(\mathrm{H}_{\mathrm{dm}}\right)+0.0182$

In Fig. 10, the dashed-dotted line shows the variation of $b$ for acrylic. The same linear fit as in oil paints was made for acrylic samples to derive the value of $b(\lambda)$, $\mathrm{b}_{\text {acrylic }}=-4.57 \mathrm{e}^{-04} \ln \left(\mathrm{H}_{\mathrm{dm}}\right)+0.0096$

In Fig. 10 the continuous line shows the variation of $b$ for gouache. The linear fit for gouache samples provided the following value of $b$

$\mathrm{b}_{\text {gouache }}=-6.68 \mathrm{e}^{-04} \ln \left(\mathrm{H}_{\mathrm{dm}}\right)+0.0102$ 


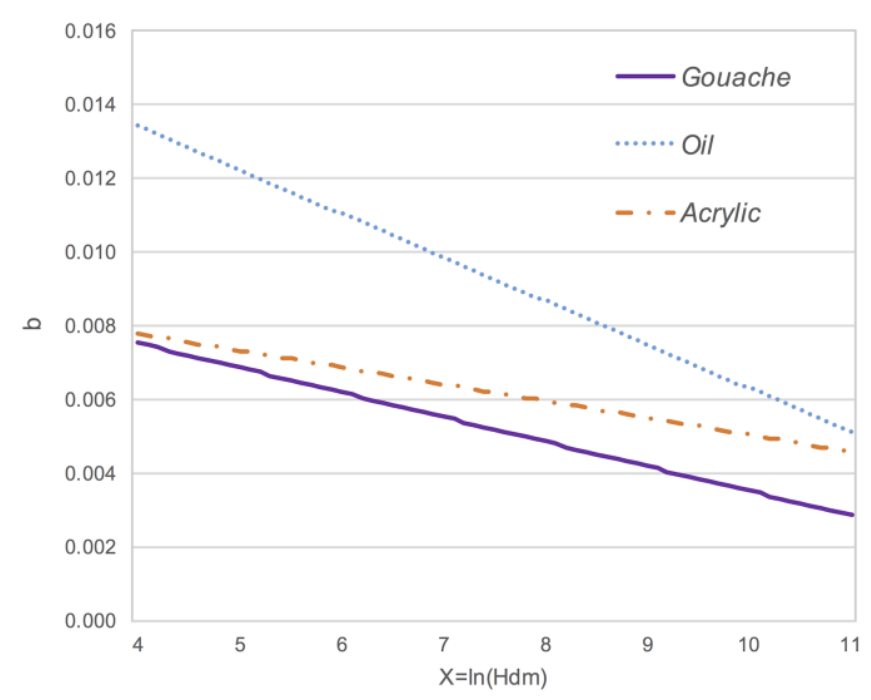

Fig. 10. Values of $b$ according to the proposed model for oil (dotted line), acrylic (dashed-dotted line) and gouache (continuous line), with the value obtained using equations (14),(15) and (16).

Taking the oil as a reference and using equation (11), the relative damage $\left(\operatorname{Rd}\left(\lambda_{\mathrm{i}}\right) / \operatorname{Rd}\left(\lambda_{1}\right)\right.$ produced by a source of illuminance that radiates at different wavelengths can be derived for a certain period of time. For instance, if the values of $\lambda_{\mathrm{i}}=627 \mathrm{~nm}$ and $\lambda_{1}=447 \mathrm{~nm}$ are considered, then $X=4, b=0.0134$ (calculated from equation (14)) and $\operatorname{Rd}\left(\lambda_{\mathrm{i}}\right)=0.0893 \operatorname{Rd}\left(\lambda_{1}\right)$.

If $X=10$, then $b=0.0047$ and $\operatorname{Rd}\left(\lambda_{\mathrm{i}}\right)=0.39 \operatorname{Rd}\left(\lambda_{1}\right)$. The value obtained indicates the relative damage of the paint depending on the time that it has been radiated and the spectral characteristics of the source used. The results indicate that radiation at shorter wavelengths has a major effect on the relative damage when it has been radiated for short periods of time. As the paint is exposed to longer periods of time, the relation between the damage at short and long wavelengths decreases. The relation that allows determining the damage behaviour in oil, acrylic and gouache paints due to the illuminant used in an exhibition provides a value that can be used to determine the most suitable type of illuminant. 
If a comparison is made with the value $b=0.0115$ given by the CIE 157 , it can be seen that this is an intermediate value, equal to the value obtained in our model for $X=4.7$.

\section{Conclusions}

The accurate estimation of the real aging of paints in art exhibitions requires knowledge of the spectral sensitivity of the paint, as well as the spectral characteristics of the incident light. The main advance of this research has been the development of a spectral model, $\operatorname{Rd}(\lambda)$, which can help to define the spectral characteristics of an optimized illuminant, allowing for the quantification of how this spectral distribution produces aging in a painting over time.

From this research, parameter $b$, which is not constant in time, was found. This parameter decreases as the paint ages. This trend is not linear in the studied materials. In the acrylic samples, $b$ decreases 1.69 times from $X=\ln \left(H_{d m}\right)=4$, and in the oil samples, it decreases 2.61 times in the same range. Therefore, the differences between the wavelengths of a specific light source are higher in young paints than in old ones. In gouache samples, the variation of $b$ is 2.63 times smaller. To determine the $b$ parameter behaviour with different materials, future studies should investigate these result with longer periods of exposure to light.

The model developed in this study provides useful information about the colour shift of a restoration process in an old painting, which can be used by the museum to estimate how much time a light source can be used to illuminate a painting without suffering a colour change that is appreciable by the visitors or, in other words, to calculate the maximum irradiance that can be applied over a painting to maintain it without a colour shift for a specific period of time. 


\section{Acknowledgments}

We would like to thank Paola Bellonni and Telmo Fernández for critical review of the manuscript.

This work has been supported by HAR 2012-31929.

\section{References}

[1] G. Pavlogeorgatos, Preservation of material cultural heritage. Thessaloniki, Greece: Paratiritis Publishing House S.A., 2003. ISBN 960-374-253-8 [in Modern Greek].

[2] D. Camuffo, R. Van Grieken H.J. Busse, G. Sturaro, Valentino, A. Bernardi, N. Blades, D. Shooter, K. Gysels, F. Deutsch, M. Wieser, O. Kim, U. Ulrych, Environmental monitoring in four European museums. Atmospheric Environment 2001;35(1):12740. http://dx.doi.org/10.1016/S1352-2310(01)00088-7.

[3] CIE 89/3:1991. On the deterioration of exhibited museum objects by optical radiation.

[4] CIE 157-2004, Control of Damage to Museum Objects by Optical Radiation, ISBN 9783901906275.

[5] G. Pavlogeorgatos, Environmental parameters in museums. Building and Environment 2003; 38 1457-1462. http://dx.doi.org/10.1016/S03601323(03)00113-6

[6] S. Mayorga, D. Vázquez, A. Álvarez, G. Hernández, J.A. Herraéz, M. Azcutia, A. Botella, Advanced daylighting evaluation applied to cultural heritage buildings and museums: Application to the cloister of Santa Maria El Paular, Renewable Energy January 2016; 85 (C):1362-1370, http://dx.doi.org/10.1016/j.renene.2015.07.01. 
[7] C. Cuttle, Damage to museum objects due to light exposure. Lighting Research and Technology, 1996; 28(1): 1-9.

http://dx.doi.org/10.1177/14771535960280010301

[8] N. Brommelle, The Russell and Abney report on the action of light on water

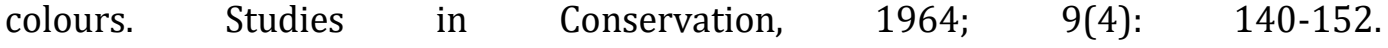
http://dx.doi.org/10.1179/sic.1964.024

[9] J. Snyder, J. Montague, Caring for your art, a guide for artists, collectors, galleries and art institutions. New York: Allworth Press; 2001. ISBN 13: 9780960711819 [10] G. Thomson, A new look at colour rendering, level of illumination, and protection from ultraviolet radiation in museum lighting. Studies in conservation, 1961; 6(2-3): 49-70. http://dx.doi.org/10.1179/sic.1961.011

[11] J.M. López-Alonso, J. Alda, Characterization of scenarios for multiband and hyperspectral imagers. SPIE, 5439 International Society for Optics and Photonics, 2004. p. 140-149. http://dx.doi.org/10.1117/12.543983.

[12] J.M. López-Alonso, J. Alda, Characterization of hyperspectral imagers and scenes: background and equipment artefacts. SPIE, 5612-34 International Society for Optics and Photonics for defence and Security, London, October 2004. p. 265-274. http://dx.doi.10.1117/12.578936.

[13] S. Baronti, A. Casini, F. Lotti, S. Porcinai, Multispectral imaging system for the mapping of pigments in works of art by use of principal-component analysis. Applied optics, 1998; 37(8): 1299-1309. http://dx.doi.org/10.1364/A0.37.001299

[14] M. Bacci, D. Magrini, M. Picollo, M. Vervat, A study of the blue colors used by Telemaco Signorini (1835-1901). Journal of cultural heritage, 2009; 10(2): 275-280. http://dx.doi.org/10.1016/j.culher.2008.05.006 
[15] Y. Zhao, R.S. Berns, Y. Okumura, L.A. Taplin, Improvement of spectral imaging by pigment mapping. Proc. IS\&T/SID 13t Color and Imaging Conference. Society for Imaging Science and Technology, 2005; 2005(1):40-45.

[16] R.S. Berns, Designing white-light LED lighting for the display of art: A feasibility study Color Research \& Application, 2011; 36(5):324-334. http://dx.doi.org/10.1002/col.20633.

[17] Y. Zhao, R.S. Berns, Image based spectral reflectance reconstruction using the matrix R method. Color Research \& Application, October 2007; 32(5):343-351. http://dx.doi.org/10.1002/col.20341

[18] R.S. Berns, Rejuvenating the appearance of cultural heritage using color and imaging science techniques. Proc. $10^{\text {th }}$ Congress of the International Colour Association AIC Colour, Granada, Spain 2005; (5):369-374.

[19] R. Lange, H. Liang, H. Howard, J. Spooner, Optical coherence tomography and spectral imaging of a wall painting. SPIE Newsroom, 2011. http://dx.doi.org/10.1117/2.1201107.003778

[20] K. Masaoka, R.S. Berns, Computation of optimal metameres. Optics letters, 2013, 38(5):754-756. http://dx.doi.org/10.1364/OL.38.000754

[21] M. Castillejo, M. Martín, M. Oujja, E. Rebollar, C. Domingo, J.V. García-Ramos, S. Sánchez-Cortés, Effect of wavelength on the laser cleaning of polychromes on wood. Journal of Cultural Heritage, 2003; 4(3):243-249. http://dx.doi.org/10.1016/S12962074(03)00049-9

[22] S. Staniforth, Retouching and colour matching: the restorer and metamerism. Studies in Conservation, 1985; 30(3):101-111.

http://dx.doi.org/10.1179/sic.1985.30.3.101 
[23] ASTM D823-95(2012)e1. Standard Practices for Producing Films of Uniform Thickness of Paint, Varnish, and Related Products on Test Panels [24] F. Viénot, G. Coron, B. Lavédrine, LEDs as a tool to enhance faded colours of museums artefacts. Journal of Cultural Heritage, 2011; 12(4): 431-440. http://dx.doi.org/10.1016/j.culher.2011.03.007

[25] ASTM D4303-10, 2010. Standard test methods for lightfastness of colorants used in artists' materials.

[26] International standard ISO 11341:2004, Paint and Varnishes. Artificial Weathering and Exposure to Artificial Radiation. Exposure to Filtered Xenon-arc Radiation, 2004.

[27] J.M. del Hoyo-Meléndez, M.F. Mecklenburg, An Investigation of the Reciprocity Principle of Light Exposures Using Microfading Spectrometry. Spectroscopy Letters. 44, 1, 52-62, Jan. 2011. ISSN: 00387010.

[28] M.D. Fairchild. Color appearance models. John Wiley \& Sons, 2013. ISBN 0-47001216-1.

[29] H. Liu, M. Huang, G. Cui, M. Luo, and M. Melgosa, Color-difference evaluation for digital images using a categorical judgment method, J. Opt. Soc. Am. A 30, 616-626, 2013.

[30] M.R. Luo, G. Cui and B. Rigg, The development of the CIE 2000 colour-difference formula: CIEDE2000. Color Res. Appl., 26:340-350, (2001). doi:10.1002/col.1049 